\title{
Healthy Control
}

National Cancer Institute

\section{Source}

National Cancer Institute. Healthy Control. NCI Thesaurus. Code C94342.

A healthy subject that is matched with an affected individual in a trial. 